\title{
Design for Healthy Horizons in a Local Community
}

\author{
Digital relations in a neighbourhood with health challenges
}

\author{
Anne Marie Kanstrup \\ Department of Planning \\ Aalborg University \\ Denmark \\ kanstrup@plan.aau.dk
}

\author{
Pernille Bertelsen \\ Department of Planning \\ Aalborg University \\ Denmark \\ pernille@plan.aau.dk
}

\begin{abstract}
Communities and social support are considered to be important for people's ability to cultivate a healthy lifestyle. Yet, digital technology for everyday health predominantly focuses on individual use and performance optimisation. In this paper, we present how we have designed a mobile application to support community collaboration around health based on a conceptual model aiming at bringing a horizon of connectedness with health to residents in a local community. The research is conducted as a long-term participatory design process in a neighbourhood with low socio-economic status and significant health challenges. We introduce a community perspective on everyday health and the codesigned application focused on local collaboration around physical activity. Via workshops with residents and community workers, we critically examine opportunities and challenges for the application's ability to form a horizon and facilitate community collaboration around health in the neighbourhood ${ }^{1}$.
\end{abstract}

\section{CCS CONCEPTS}

-Human-centred computing • Collaborative and social computing

\section{KEYWORDS}

Community, Health, Physical activity, Mobile app, Horizons

\section{ACM Reference format:}

Kanstrup and Bertelsen. 2019. Design for Healthy Horizons in a Local Community: Digital relations in a neighbourhood with health challenges. In Proceedings of Communities \& Technologies (C\&T 2019), June 3-7, 2019, Vienna, Austria. ACM, New York, NY, USA, 10 pages. https://doi.org/10.1145/3328320.3328370.

\footnotetext{
${ }^{1}$ Permission to make digital or hard copies of part or all of this work for personal or classroom use is granted without fee provided that copies are not made or distributed for profit or commercial advantage and that copies bear this notice and the full citation on the first page. Copyrights for components of this work owned by others than ACM must be honored. Abstracting with credit is permitted. To copy otherwise, or republish, to post on servers or to redistribute to lists, requires prior specific permission and/or a fee. Request permission from Permissions@acm.org.

C\&T 2019, June 3-7, 2019, Vienna, Austria.

(C) 2019 Association for Computing Machinery.

ACM ISBN 978-1-4503-7162-9/19/06 ...\$15.00.

https://doi.org/10.1145/3328320.3328370
}

\section{Introduction}

Local communities have emerged as an important entity for health promotion. Research has identified a clear relationship between residential neighbourhoods and health [1], and social support is greatly acknowledged as being important for people's ability to cultivate and maintain a healthy lifestyle. And yet, digital applications (apps), designed to help people manage their everyday health predominantly focus on individual use and performance optimisation [2,3]. Knowledge and guidance on how to design digital health support for communities is limited, but a demand exists for research that focuses on investigating digital technologies' ability to support health promotion in communities positively [4]. This study's objective is to examine how digital technology can support community collaborations around everyday health. We present how we have researched this through long-term participatory design with residents in a Danish neighbourhood identified, by the national health authorities, as an area with low socio-economic status and significant health challenges. This research demonstrates a 'situated practice of future making' [5], i.e., futures imagined and created locally with residents combining community health with digital technology in a Danish neighbourhood. An ambition in our research is to go 'beyond business as usual' [5, p. 4] in design of applications for everyday health. We pursue this ambition by exploring opportunities for community-health technology with citizens who are not usually engaged with technological innovations concerning health. Following recent investigations on who participates in the design and use of health applications [6, 7], these citizens are 'overlooked innovators' [5, p. 4]. We argue that our results represent relevant contributions to expand knowledge on health-promotion technology and provide functional support to people living with health challenges. As emphasised by [8], awareness about marginalised segments of society is important in understanding success and failure in digital design, which can include marginalised communities.

The paper is structured as follows: First, we present related work and conceptual perspectives for our research. Second, we present the site for our research and the digital application codesigned with residents in a neighbourhood. Third, we present methods used for examining the application's ability to mediate healthy relations among residents in the neighbourhood. Next, the 
findings from the analysis are presented, discussed and synthesised into four themes, which we elaborate together with discussions that examine the study's limitations and directions for future research.

\section{Background}

\subsection{A community perspective on everyday health}

Everyday health is a broad area that includes paying attention to diet, smoking, alcohol consumption, physical activity and mental health. The research presented in this paper focuses specifically on physical activity. Lack of physical activity is identified as the fourth leading risk factor of mortality worldwide [9]. The World Health Organisation (WHO) recommends that adults ages 18-64 do at least 150 minutes of moderate to intense aerobic physical activity per week or an equivalent combination of moderate activity [10]. These recommendations are difficult for many people to meet, especially those who are not socially connected. A study from 2001 on 3,342 adults in six European countries found that people with little social support from family, friends, school and work were more than twice as likely to be inactive than people with high social support [11]. Thus, research on how to bring a community perspective into the designing of digital technology for physical activity is relevant to complement the individualised performance-oriented focus dominating this design space and to reach out to people who need social support to engage in everyday health activities.

Research has pointed out that national campaigns, lecturing and other 'transfer' initiatives elicit few or no lifestyle changes [12]. Early research on communities' decisive impact on people's ability to achieve and maintain healthy living is found in Kurt Lewin's 'food habit project' from the 1940s [13]. Lewin researched underprivileged and minority groups in the United States (US), with an objective to help find solutions to social problems and develop theory and methods for research and change in the field. The project was initiated as a result of food shortages during and after World War II. In this project, housewives were identified as gatekeepers and recruited into six groups of 13-17 women each. Three of these groups received 45minute lectures that provided economic, health and food advice. The other three groups met for group discussions on how the housewives could change their families' food habits. Lewin reported that the participants who heard lectures with advice about food were affected only to a minor extent. In contrast, the group discussions exerted a strong effect on participants' motivation and ability to change habits [13]. Since these studies were conducted, social support has been identified as a persistent, central factor in cultivating and maintaining a healthy lifestyle. For example, recent research has shown how online support systems can help people form communities of practice around health, e.g., on everyday health management related to weight loss [14] or chronic illness [15]. However, most applications designed to help people engage in and maintain physical-activity levels are targeted at individuals (vs. communities) and are based on health- behaviour-change theories and features focused on supporting motivation via goals and competition [16] (vs. collaboration).

\subsection{Digital design for local community health}

Despite this knowledge and experience with online support systems, digital solutions designed to help local communities come together around health are limited. Resource networks such as time banks are among the most developed technologies for supporting hybrid collaborations on health among citizens. Timebank applications (apps) are designed to mediate resources among citizens and measure the status of resources based on time [17]. In a time bank, residents can deposit services or specific tasks that they will deliver and the time that they are willing to spend on these tasks (e.g., helping neighbourhood residents who are newly discharged from a hospital for three hours). They also can withdraw services that they need (e.g., computer support for two hours). Time-bank technology's success is considered to be its ability to mediate local social relations and include people who typically are socially excluded [17-19]. Experiences with time banks in the United Kingdom show that users typically do not see the 'banking system' as the primary value. Most users do not care whether a balance exists in the number of hours they provide and the number of hours they receive in return. Rather, the technology's ability to mediate social relations in users' local community is what is important to them, i.e., time-bank users value the attention they give to and get from residents in their neighbourhood and realise that they can support each other in their daily lives through the time bank [17].

Another example of digital design for local community health is the 'community mosaic', which was a prototype designed to research opportunities for forming social relations around nutrition. The prototype was set up on a public physical notice board, in a low-income neighbourhood in the Southern US. Residents shared photos of their food via text messages, which were displayed on the public notice board. Researchers found that the participants were very interested in sharing and learning from each other's personal experiences with food. The sharing that the digital prototype mediated increased bottom-up conversations and awareness about nutrition among the residents [4]. The researchers behind the community mosaic argued that it 'facilitated collective efforts to counter local challenges to healthy living' [4], and they labelled this as a change in power relations toward increased control by residents of health promotion in their neighbourhood.

Research on digital design for local communities in general emphasise that design is a long-term process of infrastructuring $[20,21]$ and focused on supporting capacity building in the local community.

\subsection{Imagined community: analytical lens}

Ehn et al. [5] coined the process of designing with local communities as 'future-making', in contrast to mainstream innovation focussed on market logic, 'which privileges particular crowds and particular places as centres for innovation' [5, p. 4]. Future-making refers to 'multiple futures imagined and made 
locally, in heterogeneous communities and with marginalised publics' to explore inclusive and collective approaches to technological design and use. We have embraced this perspective and complemented it by introducing the concept of 'imagined communities' as an analytical lens through which to examine futures imagined and created locally.

Benedict Anderson [22] introduced the concept of 'imagined communities' to interpret nationality as cultural artefacts. This perspective is interesting juxtaposed with our research, as it investigates how people feel as though they are part of a community. Anderson researched how nations 'have come into historical being, in what ways their meanings have changed over time, and why, today, they command such profound emotional legitimacy' [22, p. 5]. Anderson's research combines many levels of communities, and he defines a community as imagined 'because the members of even the smallest nation will never know most of their fellow members, meet them, or even hear them, yet in the minds of each lives the image of their communion' [22, $p$. 6]. Thus, Anderson brings attention to residents' construction of common images that make them feel like they are part of a community. Following Anderson, mental images of a community are supported at many levels, including national levels, e.g., by events in which the imagined community (i.e., the nation) is part of global sports games, or through symbols, such as flags and songs. In younger nations, e.g., African nations, citizens have a strong feeling of belonging to a clan community, followed by belonging to an ethnic community (sharing the same language). Anderson writes, 'Communities are to be distinguished, not by their falsity/genuineness, but by the style in which they are imagined' [22, p. 5]. An imagined community is imagined as a community because 'the nation is always conceived as a deep, horizontal comradeship' [22, p. 7]. It is because of this 'deep, horizontal comradeship' that Anderson uses the term 'community'. Anderson write, 'it is this fraternity that makes it possible, over the past two centuries, for so many millions of people, not so much to kill, as willing to die for such limited imaginings' [22, p. 7]. Print-capitalism is the key subject of analysis for Anderson, who analyses how national calendars, clocks and especially language and its use in books and daily newspapers generate a sense of national experience: 'Printcapitalism made it possible for rapidly growing numbers of people to think about themselves, and to relate themselves to others, in profoundly new ways' [22, p. 36]. This strong connectedness among people who do not even know each other personally and the role of mediating artefacts in this imagination make Anderson's perspective interesting in research on designing community technology.

Critiques of Anderson's conceptual perspective on the community focus particularly on his attention to inclusiveness in forming communities and the limited attention given to mechanisms of exclusion [23]. We are aware of this critique, but the perspective on community as imagined foreground attention to how communities are formed which is an interesting analytical lens for investigating our research question on how digital applications can support local community collaborations around everyday health.

\section{Setting}

The research presented in this paper is carried out in cooperation with residents, health professionals and community workers in a Danish neighbourhood with low socio-economic status. We refer to the neighbourhood as the EAST neighbourhood, which covers 12 square kilometres, comprising more than 16,000 residents, $60 \%$ of whom live in social housing. Regional health assessments have identified the EAST neighbourhood as a high-risk health area. In these assessments, obesity, smoking, alcohol use, low physical activity and mental health are highlighted as risk factors.

The municipality acknowledges the importance of facilitating health in challenged residential areas. For this reason, the municipality has joined forces with the four social housing associations in the EAST neighbourhood and employed community workers in a 'health shop'. The community workers focus particularly on facilitating local engagement and cooperation among residents on health issues. Specifically, community workers walk the neighbourhood and encourage residents to participate in activities. For example, they host 'quitcafé's', in which they facilitate group discussions among residents on how to quit smoking, organise play-days and other exercise activities. They also coordinate with grocery stores to spotlight healthy food. The goal of all these activities is to encourage residents to be active, responsible members of a localised healthy community. A best-practice example of this is a local gym that has developed over several years and that residents operate and manage, i.e., residents are the instructors for fitness classes and handle administration, cleaning and management of the gym on a volunteer basis. The current, principal technologies used to facilitate community collaboration around health comprise SMS, paper fliers and canvassing. Facebook and websites are used as community bulletin boards to post information about activities in conjunction with paper fliers and neighbourhood canvassing. The community workers emphasise a desire for technology that facilitates collective engagement among residents.

In collaboration with residents and community workers, we have identified physical activity as the first area of attention for research in the EAST neighbourhood [24, 25] where inactivity and low commitment to sport clubs is an identified health issue. It is a challenge for sports associations to reach out to people who are not already engaged in physical activity, and the municipality has acknowledged that new methods to facilitate physical activity are needed. On this basis, we cooperate with the municipality, community workers, the health clinic and residents in the neighbourhood to explore design alternatives for community collaboration on physical activity.

\subsection{Digital design in the EAST neighbourhood}

The research was set up as interventions to investigate digital opportunities for supporting residents in the EAST neighbourhood to create collaboration around physical activity. 
First, a participatory design intervention with 22 young adults was set up to explore opportunities for technology-supported exercise. This intervention's objective was to learn how residents can begin to feel like they are part of a healthy community. The aforementioned 22 young adults (ages 18-30) were recruited via their general practitioners (GPs). They all lived in the EAST neighbourhood, each had an average physical-activity level lower than two hours per week, and were diagnosed with depression and/or anxiety. All participants were motivated but challenged to increase their physical-activity levels. They expressed loneliness and an interest in participating in the intervention because of the opportunity to meet and connect with peers. The intervention was set up in two iterations each totalling 10 weeks and included a series of activities that aimed to engage young residents in designing digital-health solutions for the EAST neighbourhood. The participatory design intervention's results were manifested in sketches and early digital prototypes for a mobile platform that provided transparency and easy ways to join local ad-hoc health initiatives [3].

Second, a mobile application was developed on the basis of the design requirements from the participatory design intervention. This app's beta version was explored via usability tests with a broad group of men and women (ages 21-58). A total of 117 people participated in controlled lab tests and tests in natural environments accordingly. Participants comprised university students, employed adults in various fields, unemployed residents and retired citizens. They represented various physical-activity levels, self-reporting at zero to six hours of exercise per week. The usability tests resulted in revisions and development of the first version of the application, named MOVE, which was made available as a free download for iOS and Android devices [26].

\subsection{MOVE: a mobile app for local health}

Similar to the related work on digital design for community health (cf Section 2.2), the MOVE app aims to mediate healthy relations among residents in a local area-in this case, in the EAST neighbourhood - to help the community come together around everyday health. Following Anderson [22], the objective was to facilitate connectedness among residents to support their ability to imagine a healthy community. Consequently, the conceptual model for the design has been coined 'healthy horizons', referring to the ambition of bringing a horizon of connectedness with health to residents/users of the application. The app is set up around a profile in which the residential area/ZIP code links residents' profiles to other residents and activities in their local area. More than one ZIP code can be chosen. Additionally, each resident can sets up a profile with a selection of preferred exercise activities (e.g., dance, ballgames, fitness, biking, yoga or another category of the user's choice).

The entry screen lists activities in residents' neighbourhoods. Residents can choose to sign up, show interest in or skip to the next activity. To choose to participate in an activity, the user taps 'participate' ('Deltager' in Danish). The user's profile photo is then added to the activity for feedback and transparency, and accompanying text presents the total number of participants in the activity (Figure 1, left). If the user taps other participants' photos, a new screen with a detailed list of participants' names opens up (Figure 1, right). Activities are listed per day. Activities that are finished are shown until midnight, but marked in red and accompanied by the text 'the activity is finished'. In the lower part of the app, the resident can navigate the core functionalities of 'activities', 'groups', 'notifications' and 'profile' (Figure 1, left). 'Groups' present the resident with a list of 'my groups' and a list of groups within the chosen exercise categories in the resident's neighbourhood. The user can request membership in existing groups and create public or private groups, inviting and managing members. When the resident taps 'notifications' (the bell icon), a list of received notifications appears. Profile settings can be changed by tapping 'profile'.
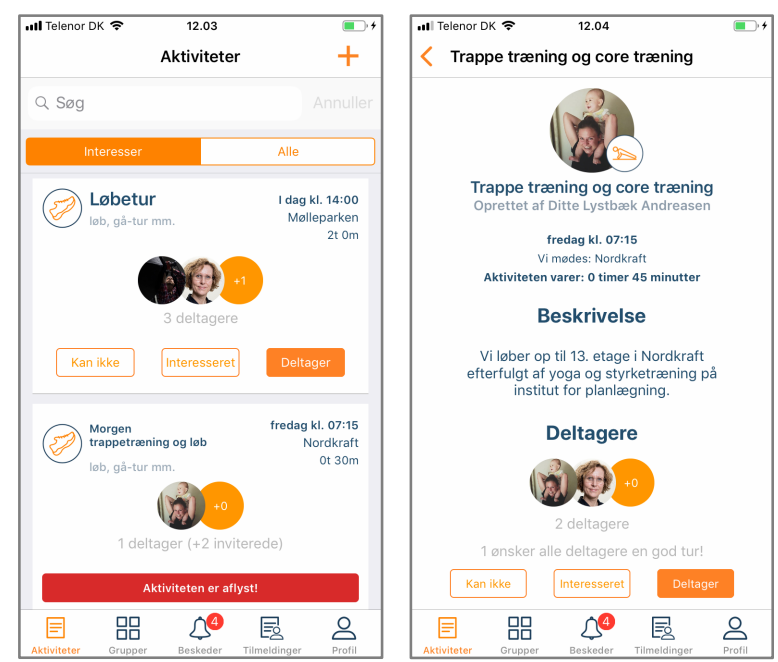

Figure 1: Left, entry screen for the MOVE application showing two activities on a list that the user can browse/scroll. Right, details are provided about the first activity on the list.

In the upper-right corner of the entry screen (Figure 1, left), the resident can tap the 'plus' sign and create activities within selected types of exercise. This functionality is fundamental to the design, as it supports a bottom-up approach to creating healthy activities in the neighbourhood, i.e., the capacity building that community workers and residents have sought. The resident chooses a name for the activity, types a location for where the participants should meet, selects a start time and expected duration, and decides who may participate, as an activity can be either public or for invited people only. Residents who sign up for activities receive a notification 30 minutes before each activity starts, or if activities are cancelled or changed. The app also has a series of screens in a deep hierarchy that users can tap to find details about activities and groups, plus pop-ups designed to provide feedback and manage groups and activities.

The usability test in particular revealed details on the importance of labels and added functionality to facilitate community workers, coaches and other organisers' ability to create a series of events in a simple manner [26]. 


\section{Methods}

The MOVE app was launched at an event in the EAST neighbourhood in summer 2018. This launch prompted a need for a critical examination of the app's ability to mediate and form healthy relations among residents in the EAST neighbourhood. As a first step in this examination, we organised workshops with groups of residents in conjunction with the launch of the MOVE app. The objective was to facilitate continued participatory design [27] of technological support for healthy relations in the EAST neighbourhood. The following subsection presents the participants and procedures for the workshops.

\subsection{Participants}

We used our contacts and knowledge of residents and groups in the neighbourhood developed through previous activities [2, 1618] to recruit a broad group of participants. We conducted four workshops with a total of 32 participants. This included: 1) the codesigners of the MOVE app/young adults diagnosed with anxiety and/or depression; 2) a self-help group for adults with anxiety and depression; 3) a group of immigrant women, including several suffering from chronic illnesses; and 4) community workers employed by the EAST neighbourhood's health centre. Table 1 presents the participating groups.

Table 1: Workshops (ws) and participants

\begin{tabular}{cl}
\hline Ws & \multicolumn{1}{c}{ Participants } \\
\hline 1 & $\begin{array}{l}\text { Six young adults diagnosed with anxiety and/or } \\
\text { depression - co-designers of the MOVE app }\end{array}$ \\
2 & $\begin{array}{l}\text { Five adults in a self-help group for individuals with } \\
\text { anxiety and depression }\end{array}$ \\
3 & $\begin{array}{l}11 \text { adult immigrant women, including several suffering } \\
\text { from chronic illnesses. } \\
10 \text { community workers employed at the municipal } \\
\text { health centre }\end{array}$ \\
\hline
\end{tabular}

\subsection{Workshop activities}

All the workshops took place in the residents' meeting rooms in the neighbourhood's community centers. We prepared a toolkit with fixed conversation themes and an identical protocol for all four workshops, but applied it flexibly, depending on the groups' resources for engaging in conversations. The workshops lasted one to three hours each, i.e., the workshops with community workers lasted three hours each, while those with the immigrant women and the self-help group lasted only one hour each. In each workshop, the MOVE app was shared with participants via links to the Apple App store and Google Play. Before the workshops, we prepared relevant, context-specific dummy content targeted at each group to support participants' ability to explore how to browse, join and create activities and groups via the app. After exploring the app with the participants, we facilitated a conversation supported by a matrix of questions that focussed on understanding how participants imagine digital health collaborations in their local community. This included conversations about the imagined value, role and use of the application. Figure 2 presents a photo from Workshop 3, with the matrix of questions displayed on a meeting table, where the nine questions created a conversation structure after exploring the MOVE app. During the conversations, the participants' key points were written on Post-it notes and placed on the matrix to facilitate shared understanding. Figure 3 presents an example from Workshop 1, with participants discussing and noting key points.

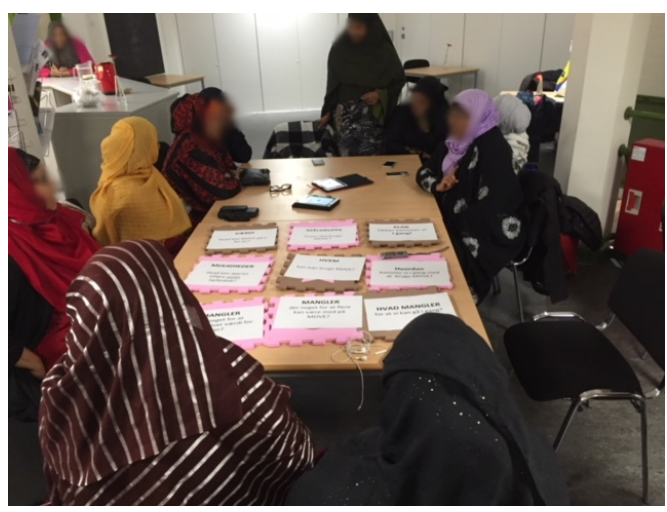

Figure 2: One of the four workshops, with the question matrix on the table.

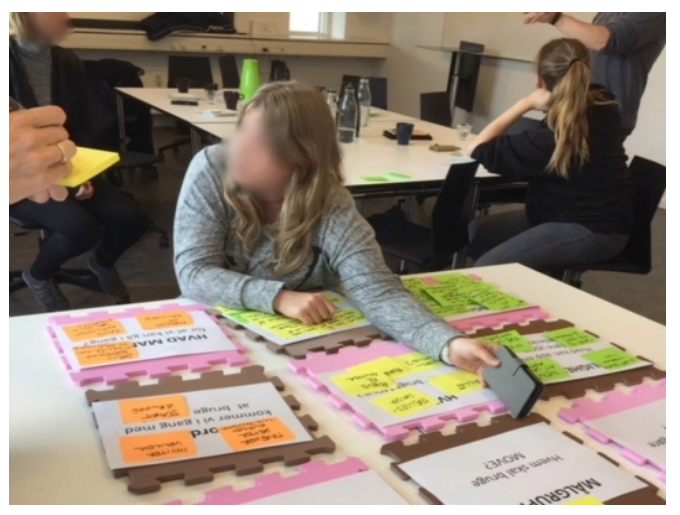

Figure 3: Participants in dialogues about key points.

\subsection{Analysis}

All conversations from the workshops were audio-recorded and transcribed. Analysis of the conversations followed the principles of thematic analysis [28]. Anderson's perspective on communities as imagined [22] guided the coding of the data with a focus on the participants imagined futures. Additionally, photos of all post-its from the conversations were examined, categorised and coded.

First, we made analyses of transcribed conversations and postits from each workshop. Second, we analysed themes across the four workshops. The results from this analysis comprised three key themes that we labelled 'the imagined healthy community', 'imagined digital health collaborations' and 'imagined challenges. [26]. The following sections present these key themes. 


\section{Findings}

\subsection{The imagined healthy community}

The residents shared multiple ideas for a future healthy community. For example, the participants in Workshop 1 had personal challenges because of mental illness. They imagined that applications like MOVE can support them in finding and joining local health activities on an ad hoc basis on days in which they have the resources: 'Impulsive' and 'spontaneous' were repeated as positive forms of local social health relations in Workshop 1. Workshop 2's participants imagined that an application like MOVE can help them expand their existing formalised social relations organised around a monthly meeting with more regular activities: 'The app could be good to bring us together in between the regular meetings, especially during winter when the weather and everything is so dark, then we could meet for coffee and maybe go for a walk' (ws2). Workshop 3's participants could not present ideas for new healthy relations. They noted how their existing network was strong and rich, with physical meetings and phone calls. They could not imagine any relevant use for an app like MOVE to mediate health activities, as their network already was very organised. However, the application spurred that they imagined opportunities to meet for physical activity: 'Maybe we could do Zumba one day' (ws3). The community workers (ws 4) imagined that residents could be supported in maintaining healthy relations. Specifically, they discussed opportunities for using the MOVE app 'as a tool to maintain the social relations and motivation that people develop during our health programmes' (ws4).

These conversations also included discussions about what constituted social relations. For some participants, the ability to follow activities via digital applications like MOVE to keep an eye on what is going on' (ws2) was a core value. In contrast, other participants imagined community collaboration around health as actual physical participation in activities and even called for organisers to have the ability to exclude people if they were only watching, but not participating (ws1).

All four workshops involved long discussions on health and brainstorming on possible scenarios for creating and maintaining healthy relations in EAST with or without the MOVE app. In Workshop 1, two male users saw a user profile with a photo of a young woman whom they did not know and imagined using the app for dating: 'I could create a walking activity and invite her and then we could talk, just me and her' (ws1). Workshop 2's participants mostly discussed opportunities to do social activities, such as meetings in cafés and other get-togethers. One participant summed up a conversation about opportunities to use the MOVE app as follows: 'It is not just for people playing football. I suggest that we create a wine club' (ws2). Workshop 4's participants suggested that the app could even be used as a hub for all activities in the neighbourhood: 'Everything that happens in EAST, you can find in this app, so if you use this app, then you know what takes place in the 'hood' (ws4). In contrast, this openness for diverse activities was a concern among some of the community workers and prompted discussions in all four workshops about when an activity is a healthy. An exchange from Workshop 4 provides an example of such a discussion among three community-workers (in short CM1, 2 and 3): CM1: 'To me, the purpose is exercise, to support people to be more physically active'. CM2: 'Yes, but if people use it to organise a sewing club, it is still good, as they will walk to the meetings, right?'. CM3: 'Well, we also want to support mental health'. CM2: 'Yes, and support the community and...'. CM3: 'Yes, exactly, and then it doesn't matter if it is biking or baking. What's important is the relations that it creates as we want to boost the community' (ws4).

To sum up, the workshops revealed multiple imagined opportunities and challenges for a healthy community in the EAST neighbourhood. Consequently, a key challenges for the MOVE app entail facilitating this diversity. Cf. Anderson, the ability to create a feeling of connectedness across this diverse group is pivotal to creating an imagined healthy community in EAST.

\subsection{Imagined digital health collaborations}

Generally, the participants in the workshops imagined multiple opportunities for using a community technology like MOVE. Most of the workshops' participants pointed to the app's value as an easy-to-use tool for mediating social health relations. To a large extent, participants' reactions to the MOVE app's interaction and navigation aspects were positive, as indicated by statements such as: 'This is really smart' (ws1). 'With this app, it's so easy to organise an activity. I can share with you when I am planning to go for a swim, and you can join me' (ws2). 'This app can help us and other organisers in the neighbourhood communicate activities to a broader audience' (ws4).

The geographical anchoring of social relations, i.e., the MOVE app's ZIP-code function as being key to activities, was discussed at the workshops. This revealed that the participants had rather diverse perspectives on the scale of community. Most participants in all four workshops emphasised geographical anchoring as the app's core positive value. For example, a participant in Workshop 2 described how she had stopped participating in health-related activities due to her geographical distance from them: 'The hospital recommended I go there [ed.: to motivation groups and exercise activities in the city centre], but I stopped. I don't have the energy anymore because I need to borrow a car, and this is just, you know...' (ws2). Community workers emphasised the value of mediating social relations locally in their neighbourhood work: 'We want to increase the residents' ability to cope and take charge via a feeling of belonging somewhere and being important to other people. This app can support this, as it has a proactive dimension that pushes activities out in the local community' (ws4). Residents appreciated the opportunity to reach out to neighbours: 'Well, you can, of course, send a text message to your neighbour, but if you don't know him so well, it really takes courage, and it can feel a bit pushy, but with this app, you can invite people in a more low-key way' (ws2).

In contrast, a minority of participants in Workshops 1 and 4 argued for including activities outside the EAST neighbourhood's ZIP code, i.e., that activities filtered by ZIP code and interests be 
combined with a broader list of activities in a larger geographical area: 'So, people can get hungry for more than they imagine they are hungry for' (ws4). In contrast, other participants argued for even more filtering functionalities, e.g., allowing filtering by age and gender: 'I want to find people my age who have the same interests' (ws1). 'You must consider gender-based filtering opportunities, as I have just signed up for a women's swimming class' (ws4, male participant). Other participants argued for broad public use to avoid any stigma: 'It's important that the app is open to a broad audience. We don't want people to think that all users in this app have mental issues' (ws2). Users in Workshops 1 and 2 in particular discussed the app as an opportunity to browse for new social activities and find the courage to engage in them: 'New relations. That is what I need. It could be, you know, maybe I could see someone in here [ed.: in the MOVE app], and then suddenly, when I have the courage, then I could join them' (ws1). These conversations present how a health community app like MOVE operates in complex environments on a scale ranging from small worlds linked together by people with personal social ties to vertical bridges across groups formed by common interests in public activities.

Several participants described how they saw the MOVE app as an alternative to Facebook and expressed appreciation for the geographical filtering: 'I really believe in this app, as it can save us from all the noise that's on Facebook. Every time I have to log on to Facebook to check up on activities, I end up doing something completely different. It's like I disappear for 10 minutes or more, and then I cannot remember what I was supposed to do. It's just noise, noise, noise' (ws1). Generally, the participants appreciated limited messaging opportunities in the MOVE app's design: 'We need to be careful not to use Facebook functionality in this app. The value of this app is that it is an alternative to Facebook' (ws1). Several participants who had bad experiences with social media raised privacy concerns. Workshop 2's participants were particularly concerned about transparency issues and feared that social workers could monitor their activities in the MOVE app. These participants stressed the app's presentation of only future activities with no record-tracking of users activities as very important. Workshop 2's participants also raised concerns about the functionality of allowing users to write comments about activities in the app and emphasised that they found value in the option to create a private group: 'The ability to create private groups is crucial. It's very important that information is not open to everybody because there is a lot of bullying, you know, and that's why we don't use these media' (ws2). In contrast, other participants called for more openness and opportunities to search for new exercise friends and for increased functionality to communicate via the app: 'We'd like to send messages to say "Hi, I'm now in the group" and stuff like that' (ws1). These conversations present how the design and use of a community-health app like MOVE require a careful balance between creating transparent and open opportunities for connecting residents around health, and providing privacy and information with which residents can cope.

\subsection{Imagined challenges}

While conversations about healthy community and digital health collaboration were generally were rich and positive, concerns also were raised about the MOVE app's. Especially socio-technical challenges were raised as a concern. For example, a participant expressed, 'The app is not a challenge; it is the context of the app that is a challenge' (ws1). The question of 'Who owns this app?' (ws4) was raised, and the app's accountability was a larger discussion theme in three workshops (1,2 and 4). 'We know that we have to try to get this app in use; it is not enough that we talk about the app and tell people how good it is, as we know that it really requires an effort to get things up and running' (ws4). In Workshop 4, the community workers agreed that an app such as MOVE and related technologies were residents' responsibility: 'We can introduce them to a technology, but it is not our task to be the coordinator here. It is the residents who have the responsibility' (ws4). Here, the app was discussed as a new, additional task for community workers (vs. a mediating artefact to facilitate community health). As a community worker expressed: 'You know, there is a thing called everyday practice, and I know that there are already so many places and systems where we have to update information and communication. And I am thinking that this is nice, and we can use this, but it is also yet another system' (ws4). The contrast between a formalised municipal health centre and an open platform for cooperation among citizens and community workers also emerged as a major concern in Workshop 4: 'If we use this [ed.: the MOVE app] in our organisation, then what kind of role does that give us compared to if this is an app run by citizens only where they control everything?' (ws4). Thus, an app's usage context, from the community workers' perspective, was interwoven into a larger ecology of technologies, tasks and regulations. Finding a space and creating a practice for a new app like MOVE in this context is a challenge.

In contrast, the participants in Workshops 1 and 2 pointed to community workers as key people for ensuring the future use of an app such as MOVE: 'It's important that the people at the health centre take charge here, as they cannot expect that we will do this. We are here because of illness, and if we are supposed to do this, if they say like "Then you do the rest yourself" - a bit like they say today when a health programme ends-then we need to have a lot of self-discipline, and we don't have that' (ws2). Workshop 1's participants supported this perspective and pointed to sports coaches in the neighbourhood, the outpatient department at the psychiatric hospital and key people in cultural institutions as being central for cultivating the use of apps such as MOVE.

Generally, conflicts were related to responsibility for the application, and it became clear that designing a socio-technical practice for a community application like MOVE is key to continued participatory design of technology-supported health in the EAST neighbourhood. The MOVE app introduces a new type of collaboration between ad-hoc resident-driven and formalised professional practices. Finding ways to approach and balance this space is a key challenge. 


\section{Discussion}

\subsection{Imagined healthy relations in EAST}

The previous section has identified multiple forms of imagined digital health collaborations. Table 2 presents a synthesis of these findings, which we interpreted as being related to four principal themes that are central to the future design and use of community health technology in the EAST neighbourhood:

1. Connections, a theme related to residents' conceptions of local collaborations: In this analysis, these conceptions range from imagining small worlds with personal ties to larger vertical bridges formed by common interests.

2. Control, a theme related to residents' conceptions of privacy and transparency: In this analysis, these conceptions range from calls for privacy and information control to a call for transparency and openness in profiles and activities.

3. Organisation, a theme related to residents' conceptions about the socio-technical organisation around health collaborations: In this analysis, these conceptions range from imagining formal professional health practices to ad-hoc informal resident-driven health.

4. Health, a theme related to residents' conceptions of everyday health: In this analysis, these conceptions ranged from imagining health as an increased physical activity level to envisioning health as increased access to follow activities.

Table 2: Imagined digital health in the EAST neighbourhood

\begin{tabular}{lll}
\hline THEME & Cortical bridges formed \\
\hline Connections & $\begin{array}{l}\text { Small worlds with } \\
\text { personal ties } \\
\text { Privacy and } \\
\text { information control }\end{array}$ & $\begin{array}{l}\text { Vy common interests } \\
\text { Transparency and } \\
\text { openness }\end{array}$ \\
Organisation & $\begin{array}{l}\text { Formal professional } \\
\text { health practices }\end{array}$ & $\begin{array}{l}\text { Ad-hoc informal resident- } \\
\text { driven health }\end{array}$ \\
Health & $\begin{array}{l}\text { Health as increased } \\
\text { physical activity }\end{array}$ & $\begin{array}{l}\text { Health as increased access } \\
\text { to follow activities }\end{array}$ \\
\hline
\end{tabular}

The results from this analysis suggest a need to find strategies for working with and across multiple imagined healthy collaborations. The analysis presented several positive imagined opportunities but especially identified that the 'deep, horizontal comradeship' [22, p. 7] that Anderson describes as key for communities is not likely to happen per se by introducing a mobile app like MOVE. Healthy collaboration is not found as 'naturally occurring' [21] in this analysis. DiSalvo [29] has highlighted the need to pay attention to conflicting issues in communities, as conflicts offer different possibilities for actions, and through this set trajectories for design: 'Uncovering and making sense of conflict is a way of identifying and working toward appropriate design action in (a) community context' [29, $p$ 26]. In line with this, the analysis presented in this paper identifies multiple and conflicting images that are important for understanding the challenges for future work on communityhealth technology in the EAST and similar neighbourhoods. The analysis is based on data from workshops with 32 residents and community workers in EAST. Approximately 16,000 citizens live in the EAST neighbourhood, with images of technology for health collaboration in a local community that likely span even more widely than those identified in this analysis. As emphasised by DiSalvo, these differences must be embraced: 'Difference is necessary to keep communities and democracy resilient. It's through difference that a community is most able to adapt to change and explore a range of possibilities for action' [29, p. 26]. Consequently, an important steps for our future research must be to design activities that support multiple perspectives on health collaborations with residents in EAST to provide a broad healthy horizon. Important steps for future research on community and technology in general include developing models for communitybased design that embrace multiple and conflicting images of collaboration in local communities.

\subsection{Healthy Horizons as a conceptual model}

The MOVE application has exemplified a design around the conceptual model 'Healthy Horizons'. This conceptual model is well-rooted in a community perspective on health and can form the basis for: 1) future research on community health technology, as the concept highlights the technology's ability to mediate connectedness around health; and 2) digital design projects, as the concept can guide development of future community technology for health. Providing images of healthy opportunities is key for healthy transformation, to support residents' ability to construct some sort of common images of a healthy community [22].

Our research shows that monitoring performance does not provide a horizon to residents who participated in this research [30]. Rather, the ability to participate in multiple forms of healthy activity is a major priority for residents, in which some form horizons merely by following/watching activities, while others participate actively in activities. Lave and Wenger's concept of legitimate peripheral participation (LPP) can be useful in combining future research on how to further unfold the conceptual model of healthy horizons to include this attention on multiple and fluid forms of participation [31]. LPP brings a developmental understanding of participants' learning in communities to the foreground. Following LPP, the individual's mastery is obtained via movements within the community of practice. This movement is typically from a peripheral position toward full participation [32, p. 83]. Thus, the LPP concept brings attention to the dynamics in community participation, as it highlights that the concept of 'central participation' does not exist [32, p. 87]. Rather, understanding and legitimising multiple forms of participation, in this case in health-related activities, is important. From this, digital design that provides a broad, healthy horizon with multiple opportunities for participation is pivotal for further research and development of healthy transformation in the EAST neighbourhood.

\subsection{Limitations and future research}

The presented analysis is based on four workshops comprising a wide variety of residents and community workers in the EAST neighbourhood. The research was conducted after the launch of 
the MOVE app. Follow-up research on actual long-term use of the app, as well as continued participatory design, is needed to provide a deeper understanding of how to support healthy horizons in local communities.

Related work on community informatics has revealed how the setting plays a major role in usage and implications from design [33]. Thus, conducting similar research in another local community is also an important step for future research to further examine the question of how digital applications can support community collaborations around everyday health.

As for most community-informatics research, this type of research is highly complex, demanding and long-term [34]. Research on long-term management and organisation of community technology is scarce, but also necessary to understand how to establish, grow and maintain community platforms like MOVE [35].

\section{Conclusions}

This paper has examined the research question of how digital applications can support local community collaborations around everyday health. The examination of a co-designed community application, MOVE, to help residents in a neighbourhood to collaborate around physical activity, has revealed multiple imagined opportunities and challenges for local health collaboration. Especially socio-technical challenges were identified as the MOVE app introduces a new way of collaboration around health in local communities.

The MOVE application exemplified our conceptual model 'healthy horizons', referring to the ambition of bringing a horizon of connectedness around health to residents/users of the application in a local community. The analysis indicates that this conceptual model can form the basis for further research and development of applications for community health. The analysis also highlights the importance of providing broad horizons and embracing diversity in designing and using digital community technology for health collaboration in a local community.

\section{ACKNOWLEDGMENTS}

This research is supported by TrygFonden. We are thankful to all residents and community workers who participated in the research activities presented in this paper. We are also thankful for the cooperation with Aalborg Municipality's health clinic in the EAST neighbourhood and for the good cooperation with the app bureau Snapp.

\section{REFERENCES}

[1] S. Macintyre, S. Maciver and A. Sooman. 1993. Area, class and health: should we be focusing on places or people?, J. Soc. Policy, 22, 02: 213-234.

[2] E. Baumer. et al. 2012. Prescriptive persuasion and open-ended social awareness: expanding the design space of mobile health. CSCW'12, ACM, New York, NY, 475-484. DOI: 10.1145/2145204.2145279.

[3] A. M. Kanstrup and P. Bertelsen. 2016. Bringing New Voices to Design of Exercise Technology: participatory design with vulnerable young adults. PDC'16. ACM, New York, NY, 41-50. DOI: 10.1145/2940299.2940305.

[4] A. G. Parker and R. E. Grinter. 2014. Collectivistic health promotion tools: Accounting for the relationship between culture, food and nutrition. Int. J. Human-Computer Studies, 72:185-206. DOI: 10.1016/j.ijhcs.2013.08.008..
[5] P. Ehn, E. M. Nilsson and R. Topgaard (eds.). 2014. Making Futures: Marginal Notes on Innovation, Design, and Democracy. MIT Press.

[6] L. S. Petersen and P. Bertelsen. 2017. Equality Challenges in the Use of eHealth: Selected Results from a Danish Citizens Survey. MEDINVO 2017: Precision Healthcare through Informatics. IOS Press, pp. 793-797.

[7] C. Showell and P. Turner. 2013. The PLU problem: are we designing personal ehealth for People Like Us?. Enabling Health and Healthcare through ICT. IOS Press. DOI: 10.3233/978-1-61499-203-5-276.

[8] L. Hespanhol et al. 2018. The Digital Fringe and Social Participation through Interaction Design (Introduction to Spcial Issue). The Journal of Community Informatics, 14(1), 4-16.

[9] Global Health Risks: Mortality and burden of disease attributable to selected major risks. World Health Organization, 2011.

[10] Information Sheet: Global recommendations on physical activity for health 18 64 years old. World Health Organization, 2009

[11] T. Ståhl et al., The importance of the social environment for physically active lifestyle - results from an international study, Social Science \& Medicine, 52 (2001), 1-10.

[12] F. Diderichsen et al. 2012. Health inequality - determinants and policies Scandinavian journal of Public Health, 40, 8:12-105.

[13] K. Lewin. 1997. Resolving Social Conflicts and Field Theory in Social Science. American Psychological Association.

[14] C. Leggatt-Cook and K. Chamberlain. 2012. Blogging for weight loss: personal accountability, writing selves, and the weight-loss blogosphere. Sociol. Health Illn. 34(7): 963-977

[15] H. Wentzer and A. Bygholm 2013. Narratives of empowerment ad compliance: Studies of communication in online patient support groups. Int. Journal of Medical Informatics, 82: e386-e394.

[16] M. Patel and A. O'Kane 2015. Contextual influences on the use and non-use of digital technology while exercising at the gym. CHI'2015, ACM, New York, NY, 2923-2932. DOI:10.1145/2702123.2702384.

[17] J. Lasker et al. 2011. Time banking and health: the role of a community currency organization in enhancing well-being. Health Promot. Practi., 12, 1: $102-115$.

[18] G. Seyfang. 2003. Growing cohesive communities one favour at a time: social exclusion, active citizenship and time banks. Int. J. Urban Reg. Res., 27, 3: 699-706.

[19] G. Seyfang. 2003. 'With a little help from my friends.' Evaluating time banks as a tool for community self-help. Local Econ., 18, 3: 257-264.

[20] C. Le Dantec and C. DiSalvo 2013. Infrastructuring and the formation of publics in participatory design. Social Studies of Science, 43(2): 241-264.

[21] G. Mosconi et al. 2017. From Facebook to the Neighbourhood: Infrastructuring of Hybrid Community Engagement. Computer Supported Cooperative Work, DOI: 10.1007/s10606-017-9291-z.

[22] B. Anderson. 1991. Imagined communities. London: Verso.

[23] A. W. Marx 2002. The Nation-State and Its Exclusions. Political Science Quarterly, 17(1): 103-126.

[24] A. M. Kanstrup, P. Bertelsen and J. Madsen. 2014. Design with the feet: Walking methods and participatory design. $P D C^{\prime} 14$, ACM, New York, NY, 5160. Doi: 10.1145/2661435.2661441.

[25] P. Bertelsen, A. M. Kanstrup and J. Madsen. 2017. Steps Toward Technology Design to Beat Health Inequality - Participatory design walks in a neighbourhood with high health risks. In A. M. Kanstrup et al. (eds.), Participatory Design \& Health Information Technology. 158-172. IOS Press, Amsterdam. Doi: 10.3233/978-1-61499-740-5-158.

[26] A. M. Kanstrup et al. 2018. MOVE: A Mobile App Designed for Social Health Relations in Residential Areas. Proceedings from MIE 2018: Building Continents of Knowledge in Oceans of Data - The Future of Co-Created eHealth. IOS Press, pp. 496-500.

[27] M. Aanestad, et al. 2017. Participatory Continuing Design: "Living with" Videoconferencing in Rehabilitation. In A. M. Kanstrup et al. (eds.), Participatory Design \& Health Information Technology. 49-59. IOS Press, Amsterdam. Doi: 10.3233/978-1-61499-740-5-45.

[28] V. Braun and V. Clarke. 2008. Using thematic analysis in psychology. Qualitative Research in Psychology 3, 2: 77-101. Doi: 10.1191/1478088706qp063oa.

[29] C. DiSalvo, 2011. Community and Conflict. Interactions, November + December 2011. DOI: 10.1145/2029976.2029984.

[30] A. M. Kanstrup, P. Berstelsen and M. B. Jensen. 2018. Contradictions in digital health engagement: An activity tracker's ambiguous influence on vulnerable young adults' engagement in own health. Digital Health, 4: 1-13.

[31] J. Lave and E. Wenger. 1991. Situated learning: Legitimate peripheral participation. Cambridge University Press.

[32] J. Lave and E. Wenger. 1999. Legitimate peripheral participation. In P. Murphy (Eds.) Learners, learning and assessment. Paul Chapman Publishing.

[33] J. Messeter et al. Migration of a sharing platform from Copenhagen to Aarhus: A live exploration of ow social innovations may travel. PDC'16: Proceedings of the $14^{\text {th }}$ Participatory Design Conference. ACM, p. 107-108. 
[34] J. M. Carroll and M. B. Rosson. 2013. Wild at Home: The Neighborhood as a Living Laboratory for HCI. TOCHI, 20, 3: Article No. 16

[35] N. Luckner et al. 2015. Setting up and Running a Sharing Service: an Organisational Perspective. $I x D \& A, 24: 63-80$. 